\title{
DOES STEREOPSIS MATTER IN HUMANS?
}

\author{
ALISTAIR R. FIELDER and MERRICK J. MOSELEY \\ London
}

\begin{abstract}
SUMMARY
Stereopsis has been one of the most popular fields of vision research for well over a century and is routinely measured in clinical practice, yet its functional significance has been largely neglected. Stereopsis is disrupted by blur, amblyopia and strabismus and is of potential value as a means of indirect screening for visual disorders in childhood. However, evidence for the functional effects of stereoscopic deficits is sparse. Recent investigations indicate that binocularity is an advantage in certain tasks, especially in the comprehension of complex visual presentations and those requiring good hand-eye coordination. The assumption derived from the evolutionary theory that stereopsis represents an adaptation by primates to arboreal life needs to be questioned. While the functional aspects of stereopsis are still not fully understood the direction that future research should take to unravel this important issue is apparent.
\end{abstract}

The need for two eyes is self evident when each is located on either side of the head, has a completely different outlook and swivels independently. Towards the top of the evolutionary tree the eyes of some species have migrated forward, so that in the human the visual fields almost totally overlap. The advantages of this arrangement are not immediately obvious and more than one vision scientist and ophthalmologist has remarked that the sole purpose of having two eyes is so that one can act as a 'spare'. This observation should not be disparaged, as amblyopic individuals are at greater risk than those without amblyopia of losing the better eye due to trauma. ${ }^{1}$ Should an amblyopic person develop an ocular disorder affecting both eyes then there is a predilection for it to affect the better eye more seriously. ${ }^{2,3}$ However, apart from a small portion of the temporal visual field which is monocular, and a

From: Academic Unit of Ophthalmology, Imperial College School of Medicine at St Mary's, Imperial College School of Science, Technology and Medicine, London, UK.

Correspondence to: Prof. Alistair Fielder, Academic Unit, Western Eye Hospital, Marylebone Road, London NW1 5YE. UK. small binocular summative effect, ${ }^{4}$ the major advantage of having two eyes is the ability to perform stereoscopic depth discrimination.

Binocular vision has been one of the most popular fields of vision research for well over a century, so here we will consider only certain aspects of: normal stereopsis, how it may be disrupted, its value as a screening tool, and its functional significance. The vast literature precludes a comprehensive bibliography, which is therefore composed mainly of recent reviews. $^{5-11}$

\section{NORMAL STEREOPSIS}

Stereopsis is the binocular perception of depth (retinal disparity). ${ }^{5}$ It provides fast and easy access to information on depth in our surroundings. By reducing the amount of scanning necessary to extract spatial information, stereopsis facilitates comprehension of complex visual experiences. ${ }^{12}$ While stereopsis is a uniquely binocular phenomenon ${ }^{5}$ there are many monocular cues which can provide information on depth including linear perspective, shadows, texture and gradients. These cues provide indirect information on depth but do not offer the quality of stereopsis, which is the only direct measurement of depth. ${ }^{5,11}$ It is possible that the development of these higher-order, so-called secondary cues is itself dependent on stereopsis, but that once established these cues are able to substitute for stereopsis, at least to a degree. The neurophysiological basis of stereopsis is beyond the scope of this article, but both magnocellular and parvocellular pathways have been implicated. ${ }^{7,11,13}$ Recently Ptito and colleagues ${ }^{14}$ using positron emission tomography (PET) scanning observed that stereopsis-induced activity begins in the posterior visual areas of the right cerebral hemisphere.

Stereopsis results from the integration of two slightly dissimilar retinal images, which requires a degree of retinal disparity (along the horizontal but not vertical meridian). It is influenced by a number of factors $5.9,11$ which are relevant to clinical testing conditions, including contrast, illumination and col- 
our. ${ }^{13}$ Stereopsis is also highly time-dependent, so that with very short exposures thresholds rise. ${ }^{11}$ While under ideal experimental conditions stereoacuity thresholds may reach $2-3$ seconds of arc, ${ }^{11}$ in clinical practice values of around 30-40 seconds are regarded as normal. The distance over which stereopsis operates is probably up to $500 \mathrm{~m}$ and improves closer to until limited by accommodation. ${ }^{5,6,15,16}$ Stereopsis and texture can interact in the perception of depth. A recent study ${ }^{17}$ found that the effect of texture at $50 \mathrm{~cm}$ was small $(8 \%)$, but when viewed further away at $200 \mathrm{~cm}$ it was greater (17\%); this difference may be functionally significant.

Stereopsis develops in early infancy between about 3 and 5 months of age ${ }^{10}$ and, depending on the test used, adult levels are not achieved until around 5-7 years. ${ }^{18-21}$ In a recent population-based study of 417 adults over 65 years of age, Wright and Wormald, ${ }^{22}$ using the Frisby test, found that stereoacuity decreased with increasing age so that full stereopsis (defined as 55 seconds of arc) was demonstrated in only $27 \%$, whilst $29 \%$ had no measurable stereoacuity. All the tested individuals were asymptomatic and none had any ocular pathology.

\section{Children \\ ABNORMAL STEREOPSIS}

About $2 \%$ of asymptomatic adults with no other disorder of binocular function have no stereopsis stereoblindness. This apart, in children, abnormal stereopsis occurs in a range of disorders such as image blur/degradation (ametropia including anisometropia, cataract), amblyopia and strabismus. Birch $^{10,23,24}$ has found that at 3-4 months of age some infants with esotropia exhibited stereopsis, but this declined thereafter. Following surgery Birch and colleagues $^{10}$ found that $35 \%$ had stereopsis of 200 seconds of arc at best. Other studies (see Birch ${ }^{10}$ ) have produced broadly similar results indicating that some children have gross stereopsis at least $4-5$ years after surgical correction. Interestingly, in the study of Birch and colleagues three children with infantile esotropia who did not receive surgery had recorded stereoacuities of 50 seconds at 57 months of age. ${ }^{24}$ However, Dobson and Sebris ${ }^{25}$ did not detect stereopsis at any time between 3 and 36 months of age in infantile esotropes even after surgical alignment, although unlike Birch they did not use prismatic correction to compensate for the deviation when taking measurements. Finally, Charles and Moore $^{26}$ reported only gross stereopsis $(<400 \mathrm{sec}-$ onds of arc) in $19 \%(n=4 / 21)$ of children who had undergone early surgery for infantile esotropia. It is pertinent that some of these children without any binocular function had previously been reported as exhibiting gross stereopsis in the early post-operative period. Following the treatment of infantile cataract few attain even a very low level of stereopsis. ${ }^{27,28}$

\section{Screening for Visual Disorders}

Walraven and Janzen ${ }^{21}$ using the TNO test on 730 children between 4 and 18 years of age observed that while poor stereopsis can occur without any associated abnormality of binocular function, this test was very sensitive in detecting amblyopes. While a few were not identified by using stimuli $\geqslant 480$ seconds of arc, by setting the level at 240 seconds all amblyopic children were detected. This finding contrasts with that of Manny and colleagues ${ }^{29}$ who, using a threshold of 730-800 seconds of arc (Lang and Frisby tests), found that while all children aged 2-5 years with strabismus had defective stereopsis, some with anisometropia but without strabismus did not. In practice, however, it is preschool children with anisometropia rather than with strabismus who pose a dilemma for screening. These studies make two interesting points: first that stereopsis is reduced in all cases of strabismus, and second, that it is so reduced that stereotests do not have to approach threshold for the purpose of screening. It follows that tests of stereopsis can be used as an indirect rather than a direct or specific method of screening for many visual disorders in childhood, and in particular those affecting binocular function. Clinically stereopsis is measured using random-dot tests ${ }^{18,19,30,31}$ which in infancy have been adapted for use according to a preferential looking paradigm (see Birch ${ }^{10}$ and Dobson and Sebris ${ }^{25}$ ). There are a number of possible pitfalls. Older children may be able to use monocular cues to produce an artefactually improved response with the Frisby test. ${ }^{29} \mathrm{~A}$ similar falsely optimistic result can also be obtained by the red/green TNO test. ${ }^{32}$ Screening is best carried out by the Random-Dot E or TNO test, with the latter threshold set at 120 or 240 seconds, while the Randot test is probably the best test to quantify stereoacuity in the ophthalmic clinic. ${ }^{21,31}$ Finally, it is important to appreciate that according to Larson and Bolduc ${ }^{33}$ the relation between visual acuity and stereopsis is idiosyncratic; with artificially induced blur no general principle could be determined. In amblyopia, the reduction in stereoacuity can be less than might be expected from the visual acuity deficit (see Von Noorden ${ }^{6}$ ).

\section{Adults}

So far we have considered the severe binocular disrupting effect of disorders with an onset in infancy or childhood. In addition to the causes mentioned already, stereopsis can be affected at any age in neurological disorders such as those arising from head trauma or, later in life, in Alzheimer's disease. The consequences of strabismus and cataract with 
onset after the establishment of binocular function are quite different. Ohtsuki and colleagues ${ }^{34}$ showed that of 25 individuals who developed a sudden-onset strabismus at from 3 to 28 years of age (mean $=12$ years), a significant number developed stereopsis despite a long period before surgical correction (mean $=6$ years). Delay in treatment did not influence outcome in this study. Thus, using Randot and Titmus tests, $16 \%$ and $43 \%$ of patients developed stereopsis of 60 seconds of arc or better, and $57 \%$ and $86 \%$ respectively achieved between 60 and 800 seconds. Laidlaw and Harrad ${ }^{35}$ reported the restoration of stereopsis, following cataract surgery with intraocular lens implantation, in 19 patients who had previously undergone a successful identical procedure on the other eye. Pre-operatively only $7 \%$ had better than 960 seconds stereopsis, while post-operatively $86 \%$ had 120 seconds or better.

\section{FUNCTIONAL SIGNIFICANCE OF STEREOPSIS}

We will begin to consider the functional consequences of stereopsis, with reference to the following quotations. Stereopsis is the 'highest form of binocular cooperation which adds a new quality to vision', 'for all purposes the only advantage of binocular vision', which 'provides a vivid and accurate relative depth experience'. 'Stereoacuity is considered as a bench mark for peak clinical performance of binocular vision'. ${ }^{8}$ Possibly tongue in cheek, Phillips ${ }^{36}$ in a Personal View in 1987 stated that 'Nature gave us two eyes so that one is spare ... Stereoscopic vision is of little value except in a few occupations'. Anecdotally it is our impression that this echoes a view which is widely, but perhaps quietly, held amongst ophthalmologists and even vision scientists. Nevertheless Phillips' comment received a speedy and robust response from $\mathrm{Sir}$ George Godber, ${ }^{37}$ who had lost one eye through trauma 68 years previously, noting 'a long held personal suspicion that few ophthalmologists know the full consequences of total loss of vision in one eye'. Although there had been some adaptation with time, he was obviously still functionally inconvenienced by the loss of binocularity over three decades previously. He reported, for instance: misjudging distances, problems with hand-eye coordination, and altered perception so that 'to the one-eyed golfer all greens are flat'. These comments are supported by Brady who wrote a book entitled $A$ Singular View ${ }^{38}$ on his experiences following the loss of one eye.

\section{Clinical Evidence}

Clinical studies investigating the functional consequences of reduced stereopsis are notably lacking, and furthermore there has been no distinction between the loss of stereopsis and those who have never had it. Indeed the latter are a neglected population from this particular research viewpoint.

Anecdotally, parents frequently report that following strabismus surgery their child's general development has improved and Rogers and colleagues noted an improvement in binocular-dependent motor skills in $35 \%$ of children after correction of infantile esotropia. ${ }^{39}$ Also relevant is the finding by Bax and Whitmore $^{40}$ in a large study of school entrants that children with strabismus had significantly higher neurodevelopmental scores (i.e. abnormal) than the 'average'. While there are a number of explanations possible for these observations they do indicate the need to investigate the relation between binocular function and neurodevelopmental skills. In an older age group, following the successful removal of one cataract, the benefits to the patient of performing the same procedure on the second eye has always been a slightly controversial topic. While there is more to this topic than binocular function, an abnormality of stereopsis could be a contributing factor. Thus the finding that stereopsis is improved by the second procedure is of great interest. ${ }^{35}$ Furthermore, in a survey undertaken by their clinicians, these patients universally considered their vision to be improved and all symptoms to be significantly alleviated by the procedure.

\section{Professional Requirements}

Certain professions require a high level of visual skills. Pilots of aircraft need excellent vision; however, the value of stereopsis in this occupation has yet to be clarified. In a study of the attrition rate during US Air Force pilot training the absence of stereopsis was not found to be a significant factor. ${ }^{16}$ This is not totally unexpected as many of a pilot's tasks are beyond the distance at which stereopsis operates. There is insufficient information to draw any firm conclusions from this study, although Snyder and Lezotte ${ }^{16}$ after reviewing the literature suggested that stereopsis does not correlate with flying ability and in most situations monocular cues suffice. However, in unfamiliar and stressful conditions (e.g. close to the ground, adverse weather) stereopsis might be beneficial. Utilising a simple test of manual dexterity - threading a loop along a bent wire (as encountered at local fêtes) - the skills of ophthalmic surgeons were compared with those of other professionals with and without stereopsis. ${ }^{41}$ Ophthalmologists performed significantly better than all other groups, and the non-ophthalmologists with good stereopsis were significantly better than those with no stereopsis but not compared with those with stereopsis of 120 seconds of arc, or worse. Other professions require a high degree of hand-eye coordination, and in a recent survey of 235 dental undergraduates Rawlinson ${ }^{42}$ showed that around 
$10 \%$ had stereopsis of 240 seconds of arc or worse and another $16 \%$ had a reduced stereoacuity of 120 seconds. Unfortunately the functional consequences of these deficits are not debated.

\section{Experimental Evidence}

Blake and $\mathrm{Fox}^{4}$ in a major review of binocular summation concluded that 'two eyes are better than one, but not by very much', and only for visual presentations with a simple configuration rather than more complex situations. Jones and Lee ${ }^{43}$ investigated binocular and monocular performance for a range of tasks some of which required stereopsis. They concluded that binocularity does offer an advantage and, contrary to Blake and Fox, ${ }^{4}$ that it exists not only for simple tasks. This is not due to binocular disparity (stereopsis arising from receiving mismatched monocular information), but rather to binocular concordance (receiving largely matched monocular information). Thus both studies considered the benefit of having two eyes to be due to probability summation and not the binocular vision which arises from observing two slightly dissimilar images.

Two recent experiments are pertinent to the functional significance of stereopsis. The first, by Wickens and colleagues, ${ }^{12}$ as mentioned, showed that three-dimensional representation facilitated and made more rapid the visualisation of a surface, especially if complex. This may have been achieved by making judgements along the viewing axis more precise, and also by reducing the amount of both effortful scanning and searching required to extract information. Interestingly, the process was not more accurate and did not confer any benefit for long-term retention of this knowledge. Most studies have focused on depth judgement and not on the motor response required by a skilled task, and the second experiment ${ }^{44}$ addressed this issue by investigating the contribution of binocular vision to the accurate programming of prehensile movements. Visually guided prehension has two components: the reach (the kinetics of hand to object) and the grasp (influenced by object distance, size, texture, composition, familiarity, etc.). The authors observed that prehensile monocular and binocular movements differed substantially. Using monocular vision, reaching latency was slower, velocity was lower; while grasping was slower with smaller grip apertures, and subjects appeared to underestimate the distance of the objects. These authors argued that binocularity contributes to the accurate programming of prehensile movements.

\section{EVOLUTION AND STEREOPSIS}

It is now time to attempt to answer the question posed by the title of this paper: Does stereopsis matter in humans? Tyler ${ }^{7}$ reflected a considerable body of opinion when he stated that primates developed stereopsis as an adaptation to an arboreal habitat, being 'faced with the tasks of locomotion through a three-dimensional realm of branches heavily masked by a veil of leaves ... The stakes for disambiguating the true distance from tree to tree were high; the price of failure was to drop many metres onto a ground inhabited by carnivorous beasts'. If this explanation is evolutionarily sound for monkeys, presumably it implies that in the human, stereopsis is largely redundant - the vision equivalent of the appendix. This arboreal theory of primate evolution is based on the observation that inhabitants of trees have evolved frontally placed eyes to gain stereopsis and claws with opposable digits and flattened nails which open out to facilitate clinging to branches, bark of trees, etc. The arboreal theory of primate evolution must now be questioned. $^{15}$ First, while the frontal eye position increases the arc of stereopsis it reduces the distance over which it is operative, and thus diminishes the ability to leap from tree to tree precisely and safely. Second, it ignores the fact that there are more squirrels than monkeys living in the world's trees, and these rodents have both sideways eyes and nonopposable digits with sharp claws. According to the visual-predation theory of evolution, primates and non-primates with close-set eyes typically rely on vision in hunting, especially at night, and might have originated from a small large-eyed nocturnal creature that inhabited bushes and trees. ${ }^{15}$ Duke-Elder ${ }^{45}$ pointed out many years ago that the frontal migration of the eyes has occurred independently on a number of occasions during evolution depending on the requirements of that species. Similarly, claw structure has been remodified, as some arboreal primates have abandoned opposable digits to redevelop sharp-tipped nails. ${ }^{15}$ Perhaps, therefore, in the human, stereopsis is not an evolutionary excess for today's requirements.

\section{CONCLUSION}

Much of the evidence presented here is somewhat conflicting, but a relatively consistent strand emerges. Humans, even pilots who require a high level of visual skills, function very well without stereopsis. However, binocularity appears to be an advantage in certain tasks, especially those in the near distance, in comprehending complex visual presentations, and those requiring complex hand-eye coordination. Stereopsis may thus be of functional benefit per se and also as a prerequisite to the development of secondary monocular cues.

Despite an enormous and continued expenditure of research effort into the basis of stereopsis, its functional benefits have been largely neglected, and 
perhaps as a consequence 'in the clinic, therefore little attention has been given to stereopsis'. ${ }^{5}$ This imbalance is all too evident in the standard clinical texts, which comprehensively cover the basis of binocular vision but contain little or nothing on its functional aspects. Furthermore the functional studies undertaken so far may not have addressed the issues of significance. To conclude, a great deal is known about the basis of stereopsis but, as Sir George Godber intimated, ${ }^{37}$ ophthalmologists and vision scientists do not adequately understand functional vision. In our quest to learn more about the usefulness of stereopsis, the recent studies of Servos and colleagues ${ }^{44}$ and Wickens and colleagues ${ }^{12}$ are of interest and may indicate a rewarding direction for future research and help us determine which questions to ask.

Key words: Binocular vision, Evolution. Screening, Stereopsis, Strabismus.

\section{REFERENCES}

1. Tommila V, Tarkkanen A. Incidence of loss of vision in the healthy eye in amblyopia. $\mathrm{Br} \mathrm{J}$ Ophthalmol 1981;65:575-7.

2. Von W Leibiger. Über unterschiedliche Erkrankungshäufigkeit des amblyopen und des nicht amblyopen Auges. Monatsbl Augenheilkd 1962;141:217-25.

3. Vereecken EP, Brabant P. Prognosis for vision in amblyopia after the loss of the good eye. Arch Ophthalmol 1984;102:220-4.

4. Blake R, Fox R. The psychophysical inquiry into binocular summation. Percept Psychophys 1973;14: 161-85.

5. Bishop PO. Binocular vision. In: Moses RA, Hart WM, editors. Adler's physiology of the eye: clinical application. St Louis: CV Mosby, 1987:619-89.

6. Von Noorden GK. Binocular vision and ocular motility: theory and management of strabismus, 4th ed. St Louis: CV Mosby, 1990:8-40.

7. Tyler CW. Cyclopean vision. In: Regan D, editor. Binocular vision, vol 9, Vision and visual dysfunction. Cronly-Dillon J, general editor. London: Macmillan, 1991:38-74.

8. Schor C. Binocular sensory disorders. In: Regan D, editor. Binocular vision, vol 9, Vision and visual dysfunction. Cronly-Dillon J, general editor. London: Macmillan, 1991:179-223.

9. Patterson R, Martin WL. Human stereopsis. Human Factors 1992;34:669-92.

10. Birch EE. Stereopsis in infants and its developmental relation to visual acuity. In: Simons K, editor. Early visual development: normal and abnormal. New York: Oxford University Press, 1993:224-36.

11. Westheimer G. The Ferrier Lecture, 1992. Seeing depth with two eyes: stereopsis. Proc R Soc Lond B 1994;257:205-14.

12. Wickens CD, Merwin DH, Lin EL. Implications of graphics enhancements for the visualisation of scientific data: dimensional integrality, stereopsis, motion and mesh. Human Factors 1994;36:44-61.

13. Stuart GW, Edwards M, Cook ML. Colour inputs to random-dot stereopsis. Perception 1992;21:717-29.

14. Ptito A, Zatorre RJ, Petrides M, Frey S, Alivisatos B, Evans AC. Localization and lateralization of stereo- scopic processing in the human brain. Neuroreport 1993;4:1155-8.

15. Cartmill M. Non-human primates. In: Jones S, Martin R, Pilbeam D, editors. The Cambridge encyclopedia of human evolution. Cambridge: Cambridge University Press, 1992:24-32.

16. Snyder QS, Lezotte DC. Prospective assessment of stereoscopic visual status and USAF pilot training attrition. Aviat Space Environ Med 1993;64:14-9.

17. Johnston EB, Cumming BG, Parker AJ. Integration of depth modules: stereopsis and texture. Vision Res 1993;33:813-26.

18. Heron G, Dholakia S, Collins DE, McLaughlan H. Stereoscopic threshold in children and adults. Am J Optom Phys Opt 1985;62:505-15.

19. Simons K. Stereoacuity norms in young children. Arch Ophthalmol 1981;99:439-45.

20. Simons K. Stereoscopic neurontropy and the origins of amblyopia and strabismus. In: Simons K, editor. Early visual development: normal and abnormal. New York: Oxford University Press, 1993:409-53.

21. Walraven J, Janzen P. TNO stereopsis test as an aid to the prevention of amblyopia. Ophthalmol Physiol Opt 1993;13:350-6.

22. Wright LA, Wormald RPL. Stereopsis and ageing. Eye 1992;6:473-6.

23. Stager DR, Birch EE. Preferential-looking and stereopsis in infantile esotropia. J Pediatr Ophthalmol Strabismus 1986;23:160-5.

24. Birch EE, Stager DR, Berry P, Everett ME. Prospective assessment of acuity and stereopsis in amblyopic infantile esotropes following early surgery. Invest Ophthalmol Vis Sci 1990;31:758-65.

25. Dobson V, Sebris SL. Longitudinal study of acuity and stereopsis in infants with or at-risk for esotropia. Invest Ophthalmol Vis Sci 1989;30:1146-58.

26. Charles SJ, Moore AT. Results of early surgery for infantile esotropia in normal and neurologically impaired infants. Eye 1992;6:603-6.

27. Birch EE, Swanson WH, Stager DR, Woody M, Everett M. Outcome after very early treatment of dense congenital unilateral cataract. Invest Ophthalmol Vis Sci 1993;34:3687-99.

28. Maurer D, Lewis TL. Visual outcomes after infantile cataract. In: Simons K, editor. Early visual development: normal and abnormal. New York: Oxford University Press, 1993:454-84.

29. Manny RE, Martinez AT, Fern KD. Testing stereopsis in the preschool child: is it clinically useful? J Pediatr Ophthalmol Strabismus 1991;28:223-31.

30. Simons K, Reinecke RD. A reconsideration of amblyopia screening and stereopsis. Am J Ophthalmol 1974;78:707-13.

31. Simons K. A comparison of the Frisby, Random-Dot $\mathrm{E}, \mathrm{TNO}$, and Randot circles stereotests in screening and office use. Arch Ophthalmol 1981;99:446-52.

32. Simons K, Elhatton K. Artifacts in fusion and stereopsis testing based on red/green dichoptic image separation. J Pediatr Ophthalmol Strabismus 1994;31:290-7.

33. Larson WL, Bolduc M. Effect of induced blur on visual acuity and stereoacuity. Optom Vis Sci 1991;68:294-8.

34. Ohtsuki H, Hasebe S, Kobashi R, Okano M, Furuse T. Critical period for restoration of normal stereoacuity in acute-onset comitant esotropia. Am J Ophthalmol 1994:118:502-8.

35. Laidlaw A, Harrad R. Can second cataract extraction be justified? Eye 1993;7:680-6.

36. Phillips CI. Personal view. BMJ 1987;295:1133. 
37. Godber G. Living with one eye. BMJ 1987;295:1351.

38. Brady FB. A singular view. Annepolis:Brady, 1985.

39. Rogers GL, Chazan S, Fellows R, Tsou BH. Strabismus surgery and its effect upon infant development in congenital esotropia. Ophthalmology 1982;89:479-83.

40. Bax M, Whitmore K. Neurodevelopmental screening in the school-entrant medical examination. Lancet 1973;2:368-70.

41. Murdoch JR, McGhee CNJ, Glover V. The relationship between stereopsis and fine manual dexterity: pilot study of a new instrument. Eye 1991;5:642-3.

42. Rawlinson A. A simple eyesight screening programme for dental undergraduates: results after 7 years. Aust Dent J 1993;38:394-9.

43. Jones RK, Lee DN. Why two eyes are better than one: the two views of binocular vision. J Exp Psychol 1981;7:30-40.

44. Servos P, Goodale MA, Jakobson LS. The role of binocular vision in prehension: a kinetic analysis. Vision Res 1992;32:1513-21.

45. Duke-Elder S. The eye in evolution, vol 1. In: DukeElder S, editor. System of ophthalmology. London: Henry Kimpton, 1958:672. 